therefore, that the rods can only amount to a small proportion of the specific antigen.

Further evidence for this view has been given by experiments on the effect of freezing sap from infected plants. Freezing had no detectable effect on the precipitin titre with antiserum; but after this treatment no rod-shaped particles have been found, either in clarified sap or in resuspended antiserum precipitates.

The evidence suggests that sap from infected plants contains at least two kinds of specific particles. One of these is the rod which can be seen with the electron microscope. The other probably occurs in much higher concentration; its size and shape are so far unknown; but the character of the precipitin reaction suggests that it may be spherical. Clarified sap from healthy sugar beet plants contains large quantities of spherical particles resolvable with the electron microscope ${ }^{3}$, and it may be that the second antigen component resembles these. Alternatively, it may have particles too small to be resolved in existing electron microscopes.

The relationship between the components is unknown. Possibly the rods are an alternative form of the spherical particles, a phenomenon known with some other viruses, or perhaps the two components are quite distinct, one being the infective particle and the other a product of the disease. \footnotetext{
H. L. NIXON
M. A. WATSON

Rothamsted Experimental Station,
Harpenden, Herts. May 9.

' Leyon, H., Arkiv Kemi, 3, 10 (1951).

'Kleczkowski, A., and Watson, M. A., Ann. App. Biol., 36, 320 (1944).

${ }^{3}$ Bawden, F. C., and Nixon, H. L., J. Gen. Microbiol., 5, 104 (1951).
}

\section{A Rare Alga from Stonehenge}

DurING a brief stay in England last year, towards the end of June a visit was paid to Stonehenge. It was noticed that several small holes in one of the fallen stones near the centre of the Circle contained green-coloured water, and since I am particularly interested in the flora of such small rain-water pools, permission to take samples was sought and readily granted. Water was spooned up, concentrated in a small freshwater plankton collecting net, and small quantities of the concentrate transferred to comparatively large jars. The following evening, on reaching my headquarters in Cheltenham, the samples were examined and most surprisingly proved to be very rich, active and nearly pure unialgal growths of Hoerratococcus drobakensis Wollenweber ${ }^{1}$. I believed then that this alga was known only from pools in granite on a small island near Dröbak in Norway; I have learnt since that there is one doubtful record from Wales.

This pretty little alga is most distinctive, bright green, with two pyrenoids placed symmetrically at opposite poles of the protoplast, across the centre of which is a clear, colourless zone; when grown in a rich nutrient solution, however, the latter is more or less completely obliterated by the extension of the chloroplast, while the whole protoplast becomes densely granular and much darker in colour.

Unlike the ubiquitous Hoematococcus lacustris, in which reproduction is in general exclusively asexual, $H$. drobakensis after a period of similar active asexual reproduction regularly enters a sexual phase, pro. ducing isogametes which on liberation conjugate to form zygotes. The whole process can be completed on agar and the resultant zygospores kept for months - at the time of writing I have a fresh series of active cultures raised from zygospores formed on agar last November. The alga is easily grown in culture, a rich growth being obtainable from the resting spores in a few days, and should prove invaluable to teachers of botany and biology as an example of a unicellular alga, for the study of both structure and behaviour and of reproduction by asexual and sexual methods.

Material was sent to Dr. E. F. Pringsheim, and I understand that Homatococcus droebakensis has now been added to the collection of pure cultures of algæ maintained by him in the Botany School at Cambridge.

Botany Department,

M. A. Pococr

University of Cape Town, May 5.

${ }^{1}$ Wollenweber, W., Ber. der deutsch. bot. Gesell., 25, 316 (1907): 28, $238(1908)$.

\section{Changes in the Colour Sensitivity of the Eye with Posture}

I REFER to J. N. Aldington's letter in the issue of Nature of July 14.

My attention was directed to apparent change of colour sensitivity of the eye with its position by my sister-an artist. She pointed out to me that if the head were held sidewise, that is, with the line joining the eyes vertical instead of horizontal, all colours in a landscape appeared to be intensified. She was in the habit of using this aid in the course of her work.

On trying the method myself, I also noticed an intensification, and more particularly in the blue of a haze in the distance.

It may, of course, be the case that there is, in fact, no greater colour receptivity in the eye in this position, but that the attention is not so much distracted by form and detail in such circumstances and so colour gets a larger share of attention than it otherwise would have. The landscape certainly seemed more vague when viewed in this position.

The effects mentioned by Dr. J. N. Aldington in Nature of July 14, p. 86, and that described above are probably connected.

Khandala Hotel,

A. BLACKIE

Blackheath,

London, S.E.3.

July 19.

I was introduced some years ago, by a friend who lives in Cornwall, to a way of looking at the landscape by leaning as far to one side as possible. In this position after a short while the view takes on a much sharper impression, particularly hills and trees against the sky which appear to be seen in much greater detail.

The observation of J. N. Aldington (Nature, July 14, p. 86) that the colour sensitivity of the eyes differs when the two eyes are in different horizontal planes suggests a possible explanation of this phenomenon.

Penwith, F. TAYLOR

The Close, Wilmington,

Dartford, Kent.

July 27. 